\title{
Ebola is diagnosed in traveler to US
}

\author{
Michael McCarthy \\ Seattle
}

A man who flew from west Africa to visit family in the United States has been diagnosed with the Ebola virus, the US Centers for Disease Control and Prevention (CDC) said on Tuesday 30 September.

In a press briefing Tom Frieden, CDC director, said he was confident that the US medical and public health system would be able to limit the spread of the deadly virus, which has killed more than 3000 people in an ongoing epidemic in west Africa.

"I have no doubt that we will control this case of Ebola in this country," Frieden said. "It is certainly possible that someone who had contact with this individual, a family member or other individual, could develop Ebola in the coming weeks. But there is no doubt in my mind that we will stop it here."

The CDC said that the patient had left Liberia on 19 September and arrived in the US the next day, traveling to Dallas, Texas. He was free of symptoms on the flight but fell ill four days later, and on 26 September he visited the emergency room at the Texas Health Presbyterian Hospital of Dallas, an 898 bed acute community hospital. The man was sent home, but on 28 September, having developed symptoms consistent with Ebola infection, he was admitted to the hospital.

Because of his symptoms and travel history, specimens were sent to be tested for the virus, and the diagnosis was confirmed as Zaire ebolavirus on 30 September at the CDC in Atlanta, Georgia, and at a Texas laboratory that is part of the CDC's Laboratory Response Network. A CDC team has been dispatched to Dallas.

The patient, who is critically ill, is in intensive care. Frieden said that the hospital was well equipped to treat Ebola patients and that there was no need to move the patient to another facility.

This is the first time an Ebola case has been diagnosed in the US and the first time the Zaire ebolavirus strain has been diagnosed outside Africa, Frieden added. Local public health officials have been identifying close contacts of the patient and will monitor them daily for 21 days. If any develop symptoms, they will be put into isolation and treated. Texas state health officials said that they had not identified anyone with symptoms of the infection to date and expected only a "handful" of people to need monitoring.

Ebola is spread through direct contact with bodily fluids from a sick person or exposure to contaminated objects, such as needles. It is not spread through the air or through casual contact. "It does not spread from someone who doesn't have fever and other symptoms, so it is only someone who is sick with Ebola who spreads the disease," Frieden said.

Because the patient is not thought to have been infectious while on his flight, health officials declined to identify the flights he took to travel from Liberia to the US. There was "zero risk" that the infection could have been transmitted to other airline passengers, Frieden said.

It is not known how the patient contracted the infection, but he did not seem to have been part of the medical response to the Ebola outbreak, Frieden noted. Health officials declined to reveal the patient's nationality.

Sporadic cases of viral hemorrhagic fever diseases similar to Ebola have occurred in the US before: one case of Marburg hemorrhagic fever and four cases of Lassa fever. All were successfully contained and no transmission occurred, Frieden said.

Cite this as: BMJ 2014;349:95980

(๑) BMJ Publishing Group Ltd 2014 